\title{
Using Insights from Cognitive Literary Study to Teach ESL / EFL Reading
}

\author{
Krystyna U. Golkowska \\ Weill Cornell Medical College in Qatar, Qatar
}

\begin{abstract}
The paper presents an attempt to use literary texts to build ESL / EFL learners' critical thinking skills and intercultural competence. The proposed approach emphasizes the dialogic nature of the writer-reader relationship in texts; informed by cognitive literary studies, it taps students' affective response to fictional characters while also grounding their instinctive understanding in close reading. A small-scale study conducted to test the effectiveness of this method is also discussed. It is claimed that the subjects, undergraduate ESL students, benefited from the approach by becoming aware of their active role in creating meaning and learning to step outside their culturally determined perspective.
\end{abstract}

With the importance of reading authentic texts well established in the field of language teaching, magazine articles, essays, and short stories for several decades now have been featured prominently in ESL / EFL course descriptions. More often than not, however, tasks and activities based on these texts tend to involve merely shallow cognitive processing. For example, literature is sometimes seen merely as a source of vocabulary and sentence-level comprehension exercises or drills in skimming, scanning, and speed-reading. What is more, even if a fictional narrative is chosen for its interesting theme, students are encouraged to talk about their personal experiences and allowed to completely depart from the text and its meaning. Consequently, important opportunities for developing critical thinking and building cultural knowledge are overlooked.

It goes without saying that reading in a foreign language is especially difficult. Challenges associated with advanced reading comprehension have been extensively discussed by researchers (for a comprehensive review see Bernhardt, 2011; Grabe, 2009; Grabe \& Stoller, 2002; Koda, 2005). At the same time, regardless of where one stands in the debate on literature learning and language acquisition, one has to agree that reading extensively is important and that reading narrative fiction can be enriching and empowering. The dilemma for ESL teachers is finding accessible texts and choosing appropriate methods of presenting them to students. The way of reading proposed in the present paper is informed by the cognitive approach to literature. It emphasizes honing students' analytical skills while also teaching them to read with pleasure and confidence.

\section{Framework Built on Insights from Cognitive Literary Studies}

Called one of the most promising developments in the humanities in recent years, cognitive literary studies draw on diverse disciplines such as psycholinguistics, neuroscience, philosophy of mind, or artificial intelligence. Although its contribution to narratology and the study of 
metaphors has been widely recognized, this approach has not yet made a discernable impact on the way literature is taught to English majors or used in ELT classrooms. Reasons for this situation are perhaps rooted in skepticism with regard to the relationship between science and liberal arts. We know that literature can teach us how our minds work, but can cognitive science teach us how to read literature? In the author's opinion, the interdisciplinary study that explores the nature of human perception and learning as context-dependent and culturally indexed can benefit not only literary critics, but also ESL / EFL reading teachers. The insights that can prove especially useful in a foreign language classroom are those related to what happens when we read and why we can find this activity fascinating. It appears that several key concepts in cognitive literary studies could be of interest to reading teachers.

Mind attribution and mind reading. First and foremost, cognitive approaches to the study of literature emphasize that engaging in reading fiction means engaging in the process of mind attribution and mind reading. This focus legitimizes a return to discussing literary characters as "real" people, an anathema in literary criticism dominated by structuralism or poststructuralism, but something "ordinary" readers yearn to do. As cognitivists explain, ascribing feelings and intentions to others and analyzing their states of mind are an everyday activity we would not be able to survive without it (Palmer, 2010; Zunshine, 2006). This is also how we read fiction. To quote Palmer (2010), "We all think of novels in terms of the mental functioning of characters. In fact, as readers, we have to be cognitivists. Otherwise we would not be able to read at all" (p. 177). Moreover, this is also why ordinary readers are interested in fiction.

From a teacher's point of view, highlighting the link between reading fictional minds and the type of mind reading practiced in real life makes literature and class activities associated with it more relevant and engaging. Many students are not familiar with literary terms and feel intimidated by approaches that emphasize stylistic and rhetorical analysis. At the same time, like all readers, they respond to fiction emotionally; they love, hate, and grow attached to protagonists, whose existence they know is purely imaginary, as if they were flesh and blood people. Vermeule's (2010) book titled Why Do We Care About Literary Characters? offers an extensive exploration of this phenomenon, which seems so perfectly "natural" that it is seldom given any thought. It makes sense to validate this insatiable interest in discovering what other people think and capitalize on our students' emotional investment to spark critical inquiry. Questions about the protagonist's ability to read the thoughts and intentions of others can be phrased in a way simple enough to be understood even by less advanced ESL / EFL students. Here are examples of some questions:

- Who or what is in the center of the protagonist's attention?

- How does the protagonist reach conclusions about other people's intentions and desires? Which of them are correct? Which of them are wrong? Is there a pattern?

- To what extent does the characters' success or failure in mind reading contribute to the development of the plot? How is it related to the theme?

- What is the protagonist's emotional profile?

Needless to say, texts differ in the amount of mind reading effort they require from readers. In Zunshine's words, 
Although all fictional texts rely on and thus experiment with their readers' ability to keep track of who thought, wanted, and felt what and under what circumstances, some authors clearly invest more of their energy into exploiting this ability than others. (2006, p. 75)

The works of Virginia Woolf or Henry James are especially challenging from this point of view, but there is no shortage of linguistically accessible short stories that an ESL / EFL teacher can reach for (see Appendix A for a list of suggested readings). Leonard Michaels's 2007 piece, The Hand, is an example of a deceptively simple text that is rich in meaning:

I smacked my little boy. My anger was powerful. Like justice. Then I discovered no feeling in my hand. I said, "Listen, I want to explain the complexities to you." I spoke with seriousness and care, particularly of fathers. He asked, when I finished, if I wanted him to forgive me. I said yes. He said no. Like trumps. (p. 109)

A lesson plan built on this short text would allow students to practice critical thinking, discuss cultural issues, or talk about style and structure (see Appendix B for examples of studentgenerated discussion questions).

Reading as "a game of chess." To encourage students' critical thinking, it is crucial to pose an important question raised by cognitivists: How do we know what we claim we know about the minds of the literary characters we so strongly care about? In other words, class activities need to emphasize grounding statements about the inhabitants of a fictional world in a close reading of the text.

Cognitive literary critics talk about reading fiction in terms of a "mental game" or "a chess game" between the reader and the writer (Zunshine, 2006, pp. 64-65). When we enter a fictional world, or "storyworld," and start orienting ourselves in it, we do so based on textual clues. As Doležel (1988) states, "from the viewpoint of the reader, the fictional text can be characterized as a set of instructions according to which the fictional world is to be recovered and reassembled" (p. 489). There are several benefits of raising students' awareness of this fact. First of all, this approach promotes a search for signals planted by the author in the text. Paying attention to details, identifying main ideas, evaluating evidence, and drawing conclusions are critical thinking skills that language learners need to practice. This in turn also highlights the active role of the reader in creating meaning. ESL learners sometimes tend to see themselves as passive recipients of knowledge and need to be taught to ask questions of a text. Furthermore, practice in playing the "chess game" with the writer helps them realize the importance of the writer-reader dialogue in all texts, which can motivate them to write with more clarity.

"The reflector figure." Another concept useful in guiding students in their reading is related to "the situated nature of all perception," the fact that

... what can be seen, what is known about the world alters with the spatial coordinates of the embodied self that is doing the looking; ... that a self is in part constituted by what it sees and by when and where it sees it ... (Herman, 2010, p. 166) 
Herman (2010) uses the term "the main internal focalizer" or "reflector figure" with reference to the character "whose vantage point provides a window on the action being recounted" ( $p$. 164). The concept of the reflector figure is easy to understand for today's learner used to visual media; moreover, it draws attention to the aspects of the fictional reality that are thematically relevant. Activities such as mapping the movement of the reflector figure or visualizing in order to fill in the gaps appeal to students' creativity and improve their comprehension of a text.

The following questions can initiate a meaningful discussion:

- Who is the reflector figure? What is in the center of his / her attention?

- How much of the fictional reality do we see through his / her eyes? What is not shown and why?

- Does the position of the reflector figure shift in the course of the story? Is this shift important? What is its function?

- What would the fictional world look like if it were presented from the point of view of another character?

Such questions can be answered orally, in writing, or even by drawing pictures, all of which involve higher order cognitive processes. Although learners' proficiency will impact the level of sophistication with which they verbalize their reflections, engaging in the activity will in itself increase their awareness of reading as a meaning-making process.

Shared thinking or "the intermental unit." Works of fiction teach us to look through the eyes of others, an indispensable precondition to developing not only empathy, but also cultural competence. A literary text almost always explores complex relationships between the mind of the protagonist and the minds of other characters; it also directly or indirectly portrays the dominant way(s) of thinking in the society depicted in the narrative. Using the term intermental unit with reference to shared thinking, Palmer (2010) observes, "Just as in real life, where much of our thinking is done in groups, a good deal of fictional thinking is done by large organizations, small groups, families, couples, friends, and other intermental units" (p. 184). He then adds, "In fact, a large amount of the subject matter of novels is the formation, development, maintenance, and breakdown of these intermental units" (Palmer, 2010, p. 184); hence, the value of literature for building intercultural competence. A discussion of intermental units will almost inevitably lead to revealing cultural schemata, not only those represented in a work of fiction, but also those used to interpret it. A literary text provides an authentic snapshot of what a given culture looks like, how it is lived, and also, even more importantly, how it is questioned from within; great books undermine stereotypes rather than propagate them. Consequently, discussing fiction creates opportunities for talking about culture without resorting to stereotypes or using the "us and them" dichotomy.

Class activities designed to analyze a text from the point of view of the relationship between the protagonist and the intermental units would revolve around the following questions:

- Who forms the dominant intermental unit?

- How does the protagonist situate himself / herself vis-à-vis the dominant intermental unit(s)? For example, does she / he identify with it, fight it, or feel alienated from it?

- How is the relationship relevant to the meaning of the story?

- What does it tell us about the culture the text represents? 
In turn, an analysis of the relationship between the reader and the text on the level of the textreader relationship would pose questions such as:

- What type of reader does the text assume in terms of background knowledge or cognitive and emotional profile?

- How much effort is the reader expected to make to understand the mind of the protagonist and his / her relationships with other characters?

- How would the relationship between the protagonist and the intermental unit differ in students' L1 culture?

- In what ways is the L2 reader different from the intended reader?

Asked to reflect on their own culture and the target culture, students build intercultural competence (Byram, 1998; Byram, Nichols, \& Stevens, 2001; Kramsch, 1993, 1998; Kramsch, Cain, \& Murphy-Lejeune, 1996), one of the most significant benefits of reading literature in a foreign language. Again, the above sample questions can easily be modified to accommodate a less proficient reader while still encouraging critical thinking.

In summary, within the framework based on cognitive literary studies, students' affective response to fictional characters would be validated, but it would also be grounded in close reading. One can envision that this approach would also raise students' awareness of the dialogic nature of the writer-reader relationship. Classroom activities would explore the extent to which the protagonists' success or failure in reading other characters drives the plot and contributes to the development of the theme. On the level of the text, attention would focus on the structure of the storyworld, with special emphasis on the interaction between the protagonist and the intermental unit(s). On the level of the reader-text interaction, students would analyze the cognitive profile of the storyworld as mirroring the culture that the text is part of; at the same time, they would be encouraged to critically examine their own perspective. Thus they would be able to reach the "third place" (Kramsch, 1993), where it is possible to temporarily step outside the culturally determined boundaries of the self.

\section{Application}

The above-described approach was used with undergraduate students at Weill Cornell Medical College in Qatar. The students were at the high intermediate and advanced levels of proficiency in English, as determined on the basis of their TOEFL scores, SAT verbal scores, and institutional testing. Coming from an oral culture, they had little previous experience of interpreting or even reading fiction. Since the goals of the Reading / Writing course they were taking included enculturation and critical thinking in addition to building communicative competence, using authentic literary texts in a way that would best help achieve these aims in a short period of time was especially important.

Overall, 45 students participated in the pilot project that involved a module based on the cognitive approach to literature. Information about the effectiveness of the module was collected through a pre-test, a post-test, a semi-structured interview, and an end-of-thesemester reflective evaluation form.

In the first week of the semester, the students were asked to read Hemingway's short story, Cat in the Rain (1987) and write for 30 minutes in answer to the open-ended question "In your opinion, what is the story about?" The answers were analyzed for the occurrence of comments on the characters' way of thinking and ability to read the minds of others; references to stereotyping or cultural differences were also noted. Although the expected length of the 
assignment was approximately 250 words, the responses actually produced by students ranged from 50 to 150 words. Approximately $85 \%$ of students merely listed what the characters did and most of them dismissed Cat in the Rain as a story in which nothing happens. Only $12 \%$ focused on the wife's emotional profile and interpreted her wish to get the cat as a sign of being bored or sorry for the animal. No more than $4 \%$ saw the interaction between the wife and the husband as important at all in the story. Interestingly, even in terms of summarizing the plot, the students did not do very well; for example, all of them completely missed the fact that, in the end, the wife gets a different cat from the one she originally wanted. Evidently, their lack of interpretative skills was compounded by their inability to pay close attention to the text.

After this pre-test, the students were given a brief introduction to the model described in the first part of the present article. To practice applying the concepts of mind reading, the reflector figure, or the intermental unit in their own interpretation, they were asked to generate their own discussion questions for Michaels' The Hand. This assignment and the class discussion that followed proved that the students had grasped the idea of reading actively (see Appendix B for a compilation of submitted questions).

As a post-test, two weeks later, the students were asked to read and interpret another short story, No Speak English, an excerpt from The House on Mango Street by Sandra Cisneros (1991, pp. 76-78). The prompt for the assignment was identical to the previous one. This time, the responses revealed a deeper understanding of the text. Only $7 \%$ of students saw Cisneros's narrative mainly as "a story about Mamacita, a fat woman, who is lazy and doesn't want to learn English." Approximately $75 \%$ of students identified the reflector figure and noticed the existence of multiple perspectives in the storyworld; $62 \%$ referred to the concept of the intermental unit to discuss the shared thinking of the neighborhood, and $32 \%$ commented on how the reflector figure distances herself from it. Thus it appeared that the concepts in the module were effectively used as tools to unlock the meaning of the narrative.

The class activities that followed the post-test aimed at expanding and enriching the students' initial response to the text. They included mapping the fictional world as depicted by the reflector figure, imagining what it would look like if presented from the point of view of the other characters, and writing a movie script based on the story. The students ended with a better understanding of Mamacita's nearly complete isolation; consequently, they developed a more sympathetic view of her plight. During these activities, the students also brought up the concept of "the third place," observing how the narrator situates herself in relation to the intermental unit, as both a member of the community and somebody with a different point of view. They also admitted that their own perspective was culturally determined. Their lack of knowledge about the situation of immigrants such as Mamacita, views on the role of women, and conviction about the importance of learning English were all important factors in passing a negative judgment on the character.

The end-of-the-semester semi-structured interviews and evaluation forms validated the usefulness of the module. Out of 44 students, 32 stated their interest in reading fiction in the future had increased significantly and 33 said they appreciated the game-like aspect of this type of reading; all the respondents were eager to use the same model of reading in the next semester. Since these students want to be medical doctors, they also appreciated the link between becoming expert readers of fictional minds and readers of patients coming from a wide social and cultural spectrum. 


\section{Concluding Thoughts}

The module discussed here was introduced to a small number of students. Consequently, no valid conclusion as to its effectiveness can be reached. Nevertheless, the response to it was very encouraging. The value of this approach is that it builds on students' instinctive interest in fiction to sharpen their critical thinking. It also shows them how to reflect on their own culture and the target culture, an experience that can be liberating and rewarding.

\section{Author Note}

Krystyna U. Golkowska, Pre-Medical Education, Weill Cornell Medical College in Qatar.

Correspondence concerning this article should be addressed to Krystyna U. Golkowska, PreMedical Education, WCMC-Q, Qatar Foundation, Education City, P.O. Box 24144, Doha, Qatar. E-mail: krg2005@qatar-med.cornell.edu 


\section{References}

Bernhardt, E. (2011). Understanding advanced second-language reading. New York, NY: Routledge.

Byram, M. (1998). Teaching and assessing intercultural communicative competence. Clevedon, England: Multilingual Matters.

Byram, M., Nichols, A., \& Stevens, D. (Eds.). (2001). Developing intercultural competence in practice. Tonawanda, NY: Multilingual Matters.

Cisneros, S. (1991). The house on Mango Street. New York, NY: Vintage Books.

Doležel, L. (1988). Mimesis and possible worlds. Poetics Today, 9(3), 475-496.

Grabe, W. (2009). Reading in a second language: Moving from theory to practice. New York, NY: Cambridge University Press.

Grabe, W., \& Stoller, F. (2002). Teaching and researching reading. New York, NY: Pearson Education.

Hemingway, E. (1987). Cat in the rain. In The complete short stories of Ernest Hemingway (Finca Vigia ed., pp. 127-132). New York, NY: Charles Scribner's Sons.

Herman, D. (2010). Narrative theory after the second cognitive revolution. In L. Zunshine (Ed.), Introduction to cognitive cultural studies (pp. 155-175). Baltimore, MD: Johns Hopkins University Press.

Koda, K. (2005). Insights into second language reading: A cross-linguistic approach. New York, NY: Cambridge University Press.

Kramsch, C. (1993). Context and culture in language teaching. Oxford, England: Oxford University Press.

Kramsch, C. (1998). The privilege of the intercultural speaker. In M. Byram \& M. Fleming (Eds.), Language learning in intercultural perspective: Approaches through drama and ethnography (pp. 16-31). New York, NY: Cambridge University Press.

Kramsch, C., Cain, A., \& Murphy-Lejeune, E. (1996). Why should language teachers teach culture? Language, Culture and Curriculum, 9(1), 99-107. http://dx.doi.org/10.1080/07908319609525221

Michaels, L. (2007). The hand. In L. Michaels, Collected stories (p. 109). New York, NY: Farrar, Straus and Giroux.

Palmer, A. (2010). Storyworlds and groups. In L. Zunshine (Ed.), Introduction to cognitive cultural studies (pp. 176-192). Baltimore, MD: Johns Hopkins University Press.

Vermeule, B. (2010). Why do we care about literary characters? Baltimore, MD: Johns Hopkins University Press.

Zunshine, L. (2006). Why we read fiction: Theory of mind and the novel. Columbus, OH: Ohio State University Press. 


\section{Appendix A \\ List of Recommended Texts}

Bradbury, R. (1997). The long rain. In R. Bradbury, The illustrated man (pp. 78-96). New York, NY: Morrow \& Company.

Bradbury, R. (1997). The veldt. In R. Bradbury, The illustrated man (pp. 7-25). New York, NY: Morrow \& Company.

Chopin, K. (2006). The story of an hour. In S. Marcus (Ed.), A world of fiction: Twenty timeless short stories. White Plains, NY: Pearson Education.

Cisneros, S. (1991). The house on Mango Street. New York, NY: Vintage Books.

Hemingway, E. (1987). Cat in the rain. In E. Hemingway, The complete short stories of Ernest Hemingway (Finca Vigia ed., pp. 127-132). New York, NY: Charles Scribner's Sons.

Hemingway, E. (1987). A clean well-lighted place. In E. Hemingway, The complete short stories of Ernest Hemingway (Finca Vigia ed., pp. 288-291). New York, NY: Charles Scribner's Sons.

Hemingway, E. (1987). Hills like white elephants. In E. Hemingway, The complete short stories of Ernest Hemingway (Finca Vigia ed., pp. 211-214). New York, NY: Charles Scribner's Sons.

Hemingway, E. (1987). The killers. In E. Hemingway, The complete short stories of Ernest Hemingway (Finca Vigia ed., pp. 215-222). New York, NY: Charles Scribner's Sons.

Michaels, L. (2007). The hand. In L. Michaels, Collected stories (p. 109). New York, NY: Farrar, Straus and Giroux.

Tyler, A. (2006). Teenage wasteland. In S. Marcus (Ed.), A world of fiction: Twenty timeless short stories (pp. 210-218). White Plains, NY: Pearson Education.

Vivante, A. (2006). Can-can. In S. Marcus (Ed.), A world of fiction: Twenty timeless short stories (pp. 4-5). White Plains, NY: Pearson Education. 


\section{Appendix B \\ Student-Generated Discussion Questions}

\section{Questions for Michaels' The Hand:}

Who is the "I"? What do we know about him?

Where did the narrated event happen? What kind of setting can you visualize for it?

How much do we know about the characters? What kind of mind reading is shown as going

on in the story?

How does the father feel about smacking his son?

Why doesn't he tell us what made him angry before he hit him? Is it important?

Why do his feelings change? How do we know that he feels guilty?

Who is the better mind reader, the father or the son?

Who wins in this situation and why?

How do you feel about the father's problem? Is what he did acceptable? What kind of person is he?

What about the son's behavior? What does it tell us about the society he lives in?

Why is the title The Hand? Can you think of a different title?

What would the story be like if it were told by the son? 